\title{
PENGARUH BUDDHISME TERHADAP NEO-KONFUSIANISME DI CINA
}

\section{Lasiyo}

Fakultas Filsafat, Universitas Gadjah Mada

Email: lasiyo@ugm.ac.id

\section{Abstrak}

Studi ini dimaksudkan untuk menggali dan menemukan pengaruh filsafat Buddhisme dari India terhadap Neo-Konfusianime di Cina, dengan menggunakan metode hermeneutika filosofis, yang unsurnya meliputi deskriptif, kesinambungan historis, dan reflektif. Simpulan yang dapat dirumuskan meliputi: pertama, Buddhisme dari India dapat diterima dan berkembang pesat di Cina karena ketidakpuasan masyarakat terhadap konfusiansime dan taoisme. Kedua, Neo-Konfusianisme yang muncul sebagai bentuk reaksi dari para penganut Konfusianisme terhadap perkembangan Buddhisme di Cina, namun Neo-Konfusianisme banyak mengadopsi ajaran Buddhisme dan Taoisme. Ketiga, para penganut Konfusianisme menyadari bahwa untuk bersaing dengan Buddhisme perlu memberikan pemikiran filsafat yang diambil dari pemikiran filsafat Cina klasik dan disesuaikan dengan situasi dan kondisi masyarakat. Keempat, Neo-Konfusianisme mengajarkan metafisika, dan etika, yang masih bersifat teoritis sehingga belum berhasil memperbaiki perekonomian dan kesejahteraan rakyat. Kelima, Neo-Konfusianisme dalam ajarannya merekonstruksi kembali pemikiran filsafat yang dianut masyarakat tradisional maupun mengambil beberapa pemikiran Buddhisme.

Kata kunci: Buddhisme, Neo-Konfucianisme, metafisika, dan etika

\section{Abstract}

This paper aims to examine the influence of Indian Buddhism toward Chinese Neo-Confucianism through philosophical perspective. This study uses library research; hermeneutical philosophical method which consists of three elements: descriptive, historical continuity and reflective. Based on data analysis, conclusion can be made such as: firstly, the influence of Buddhism from India is acceptable and growth rapidly in China because people in China were unsatisfied toward Confucianism and Taoism. Secondly, Neo- 
Confusianism was a new development, borrowing much from Buddhim and Taoism, it appear as the reaction from the Confuciansim againts the development of Buddhism in China. Thirdly, the Confucianists realized that to compete with Buddhism, they have to give a philosophical thougths from the classics Chinese philosophy and adjust it to nowdays situation and people condition. Fourthly, Neo-Confusianism's thought emphasis on Metaphysics and Ethics in theoritically, therefore it have not fix the Economic and the prosperty in society. Fiftly, Neo-Confusianism reconstructed philosophical thought which the society believe and some from Buddhism .

Keywords: Buddhism, Neo-Confucianism, metaphysics and ethics.

\section{PENDAHULUAN}

Pergaulan antarbangsa telah terjadi saling pengaruh mempengaruhi dan membawa berbagai dampak dalam kehidupan manusia antara lain bidang kebudayaan, filsafat, dan agama telah terjadi saling bertemu pengaruh mempengaruhi antara satu dengan yang lain. Kondisi semacam ini di benua Asia sudah terjadi sebelum masehi, seperti yang dialami pengaruh Filsafat India ke dalam filsafat dan kebudayaan Cina.

Buddhisme mulai masuk di daratan Cina pada pertengahan abad pertama Masehi yang pada waktu itu Cina di bawah pemerintahan Kaisar Ming (58-78 Masehi) (Fung Yu Lan, 1960: 241), yang dalam kehidupan masyarakat sudah berkembang Filsafat Konfusianisme, Legalisme, dan Taoisme. Konfusianisme sebagai aliran filsafat yang dipelopori oleh kaum terpelajar yang ahli dalam kitab-kitab klasik. Pada umumnya mereka bekerja menjadi guru dan memberikan pelayanan dalam upacara-upacara ritual serta dalam pementasan musik. Konfusinime menekankan ajaran etika baik untuk pribadi maupun untuk para penyelenggara negara. Menurut Konfusianisme, pemerintahan yang baik hendaknya mengusahakan kebahagiaan dan kesejahteraan rakyat.

Legalisme atau $\mathrm{Fa}$ Chia adalah aliran filsafat yang dipelopori oleh orang-orang yang ahli dalam bidang hukum yang pada umumnya bekerja menjadi penasihat-penasihat pemerintah, dengan mengajarkan teknik-teknik pemerintahan dan hukum. Pemerintahan yang baik hendaknya didasarkan pada kitab undang-undang yang tetap dan 
tidak didasarkan pada pendapat orang berilmu baik dalam bidang pemerintahan maupun bidang moral. Legalisme menekankan pada aspek hukum atau peraturan perundang-undangan dalam menjalankan pemerintahan. Oleh karena itu, banyak didukung oleh para pejabat pemerintah.

Taoisme merupakan aliran filsafat yang didukung dan dipelopori oleh orang-orang terpelajar yang kemudian mereka hidup menjauhkan diri dari realitas kehidupan di tengah-tengah masyarakat. Taoisme lebih menekankan pada usaha ketenangan dan keselamatan jiwa dengan mengikuti pola hidup menyesuaikan dengan hukum alam semesta. Untuk mencapai kebahagiaan hidup maka manusia mempaktekkan wu wei yang artinya tidak berbuat hal-hal yang bertentangan dengan hukum alam semesta. Oleh karena itu, manusia hendaknya hidup selaras dan dekat dengan alam, seperti hidupnya para, nelayan, petani dan biarawan. Manusia hidup sederhana, rendah hati, sehingga orang memperoleh ketenangan dan kebajikan. Untuk menjaga keserasian dan harmoni dengan alam semesta maka perlu diadakan upacara upacara ritual. Taoisme memandang bahwa dunia ini dinamis dalam arti selalu terjadi perubahan-perubahan yang silih berganti di dalam alam semesta. Dalam hubungan ini akan dikaji pengaruh Buddhisme terhadap filsafat Neo-Konfusianisme yang berkembang di Cina.

\section{PEMBAHASAN}

Buddhisme yang masuk di Cina bersintesis dengan aliran-aliran Cina terutama Konfusianisme dan Taoisme. Hasil paling nyata dari pertemuan alam pikiran ini adalah Mazhab Buddhisme Ch'an. Buddhisme Ch'an mengajarkan bahwa dalam kepercayaan bahwa pikiran harus dijaga agar tetap murni dan cerah. Pikiran dapat menangkap kebenaran mendasar alam semesta, kemudian dapat memperoleh kodrat Buddha, nirwana atau keselamatan jiwa. Di sinilah dalam pemikiran filsafat Cina Mazhab Buddhisme Ch'an, bahwa nirwana atau keselamatan jiwa tidak hanya diperoleh melalui Buddhisme, Taoisme, atau Konfusianisme saja, akan tetapi perlu kelenturan untuk mensintesakannya. Neo-Konfusianisme merupakan aliran yang muncul sebagai reaksi terhadap masuk dan 
berkembangnya Buddhisme di Cina.

Masuknya Buddhisme ke Cina merupakan suatu peristiwa bersejarah dalam hubungan kebudayaan antara Cina dengan India. Hal itu juga mempunyai arti yang jauh melebihi kedatangan suatu agama begitu saja. Bagi segenap bangsa Cina, entah mereka menerima atau menolak Buddhisme, berarti untuk selanjutnya dunia dipandangnya secara baru, serta alam semesta dipahamkan sebagai sesuatu yang sangat berbeda dibanding pemahaman yang sudah ada (Creel, 1953: 186).

Pada awalnya Buddhisme Hinayana masuk ke Cina, kemudian Mahayana yang pada gilirannya mendapatkan simpati besar dari masyarakat Cina. Buddhisme dapat masuk di Cina dan mendapat simpati masyarakat antara lain: pertama, keadaan masyarakat Cina pada waktu itu sangat menderita karena terjadinya peperangan dan pemberontakan yang menghancurkan masalah ekonomi dan menimbulkan kemelaratan bagi orang banyak. Rakyat merasa kecewa terhadap Konfusianisme dan Taoisme yang tidak dapat memperbaiki nasib rakyat. Buddhisme dapat memberikan penghiburan kepada rakyat yang menderita walaupun tidak dapat memperbaiki keadaan ekonomi dan mensejahterakannya. Penghiburan ini berupa ajaran bahwa manusia sesudah mati akan masuk nirwana dan akan hidup bahagia. Ajaran tentang kehidupan sesudah mati tidak begitu mendapat perhatian dari filsuf Konfusianisme.

Kedua, manusia yang tidak dapat menyelesaikan persoalan hidup sehari-hari kemudian akan masuk ke biara-biara; di situ mereka memperoleh ketenteraman jiwa dan jaminan hidup sehingga seolaholah mereka mereka bebas dari kesulitan ekonomi yang melanda sebagian besar wilayah Cina.

Ketiga, menurut ajaran Buddhisme, khususnya menurut aliran Mahayana, bahwa setiap penganut Buddhisme dapat memperoleh keselamatan, sedangkan dalam Konfusisme hanya kaum terpelajar yang mampu mempelajari dan mengamalkan kitab klasik yang akan hidup bahagia, begitu pula menurut Taoisme, orang yang bahagia adalah orang yang hidup dekat dengan alam.

Dalam pemikiran masyarakat Konfusianis, ide tentang Tuhan dan kehidupan sesudah mati tidak ditolak, namun tidak ditekankan. 
Konfusius menerima sesuatu yang telah dipercaya oleh masyarakat tentang Tuhan dan kehidupan sesudah mati. Dalam benak bangsa Cina, termasuk Konfusius, langit dan kehidupan sesudah mati tidak didefinisikan secara jelas dan dogmatis, namun secara samar-samar diakui sebagai yang konkret (Yong Choon Kim, 1973: 53). Fakta ini sangat menarik untuk dicatat karena kebanyakan orang keturunan Cina memperhatikan pemujaan terhadap leluhur dan membuat sesajian berupa makanan secara teratur. Namun demikian, terdapat perhatian yang terbatas terhadap kehidupan sesudah mati itu sendiri. Jadi, maksud dari pemujaan dan pemberian sesaji berupa makanan bukan demi keuntungan orang yang telah meninggal melainkan bagi orang yang masih hidup. Perspektif ini dapat dipandang sebagai perwujudan dari sudut pandang yang pragmatis dan mementingkan keduaniwian. Dalam kaitannya dengan ini, Thompson (1969: 10) mengatakan:

"Sama sekali tidak ada tempat bagi ruh. Tao, berfungsi melalui bekerjanya yang dan yin, menghasilkan perwujudan yang lebih kasar, material, dan perwujudan yang lebih halus, spiritual. Manusia adalah kombinasi dari semua ini, dan karena kematiannya manusia akan kembali ke Bumi (merupakan yin) sedangkan kombinasi unsur akan naik ke kawasan Langit yang terang dan halus (merupakan yang)."

Konfusius lebih memperhatikan pemahaman aspek kehidupan dunia dari pada aspek kematian (Legge, 1893: 241). Acuan ini menunjukkan bahwa Konfusius menolak untuk berspekulasi atau memberikan penegasan dogmatik tentang eksistensi ruh ataupun kehidupan sesudah mati, meskipun dia tidak menolaknya. Di sini kita menemukan sifat humanistik yang mendasar dari pemikiran Konfusius (Yong Choon Kim, 1973: 53).

Pusat perhatian Konfusianisme dapat dibagi menjadi enam kategori, empat meliputi dunia kehidupan dan dua kehidupan sesudah kematian: pertama, melindungi hidup dan kekayaan: sehat dan umur panjang, menghindarkan kecelakaan, dan mengusir ruh jahat. Kedua, menyesuaikan diri dengan tertib alam: kemurahan dari para dewa, mengendalikan musim hujan dan musim kemarau, hati-hati dalam 
memilih tempat unfuk bangunan dan pekuburan sehingga tidak mengacaukan "energi" yang dipercaya terdapat di dalam alam, dan perlindungan dari dewa penjaga desa dan kota. Ketiga, damai dan selaras dalam kehidupan rumah tangga: kemurahan dari paradewa yang melindungi perapian dan gerbang, anak untuk menjaga garis keluarga, mudah melahirkan anak, melindungi anak, kesejahteraan para leluhur. Keempat, sukses di dalam perjuangan hidup: kemurahan dari para dewa di dalam pertanian, kesuburan, pertukangan, dan kemakmuran. Kelima, pembebasan dari siksaan neraka: pengampuan dosa, terhindar dari penderitaan. Keenam, kelahiran kembali yang menyenangkan: reinkarnasi di dalam keluarga yang kaya, kesempurnaan moral di dalam Buddha, dan surga Tao (Cohen, 1987: 290).

Meskipun kehidupan sesudah mati tidak disebutkan dengan jelas, dan hal tersebut dapat juga tergantung kepada T'ien. Kondisi roh sangat erat berkaitan dengan perilaku orang selama masa hidupnya, yang menentukan si individu akan masuk surga atau neraka.

Ajaran-ajaran filsafat yang ditimbulkan oleh Buddhisme T'ien t'ai dan Buddhisme Hua-yen dalam menyelesaikan masalah yang dipersengketakan antara pengertian-pengertian khusus partikular dengan umum universal, subjektif dengan objektif, lahiriah dan mengutamakan kesamaan. Selain itu, ajaran-ajaran filsafat ini juga menggaris bawahi ajaran "satu dalam semua dan semua dalam satu". Buddhisme di Cina mempunyai kedudukan yang penting dalam membela gagasan mengenai penyelamatan jiwa (dari lingkaran kelahiran kembali) secara umum, dan memberikan peluang yang leluasa bagi pencerahan secara tiba-tiba.

Buddhisme mempengaruhi kebudayaan dan filsafat Cina, tetapi Buddhisme sendiri secara diam-diam dipengaruhi unsur-unsur kebudayaan dan filsafat Cina seperti Konfusianisme dan Taoisme. Di dalam terjemahan-terjemahan secara berturut-turut selama berabadabad mengenai istilah nirwana-yang diawali dengan terjemahan "kelepasan melalui kepadaman (nafsu)" yang berakhir dengan terjemahan "penyempurnaan penuh"-dapat dengan mudah disimak adanya pengaruh Konfusianisme. Hasil paling menonjol dari pertemuan alam pikiran ini ialah mazhab Ch'an, yang boleh 
dikatakan merupakan perpaduan antara Buddhisme India dengan sudut pandangan Taoisme Cina. Di sinilah bisa dilihat kelenturan filsafat Cina. Ia dipengaruhi Buddhisme, tetapi juga mempengaruhi Buddhisme. Namun demikian Cina tidak kehilangan jati diri dan identitasnya, yakni keharmonisan.

Buddhisme Ch'an merupakan sebuah mazhab di Cina yang berkembang sejak abad ke-10 dan kemudian pengaruhnya masuk ke Jepang. Sebagai ajaran tersebut merupakan hasil ciptaan alam pikiran Cina di bidang kefilsafatan-keagamaan. Diawali dengan pengutamaan tafakur, mazhab ini berlanjut dengan ketentuanketentuan asasi seperti: mengajar tanpa menggunakan kata-kata, mengacu langsung kepikiran, menjadi Buddha dengan menyadari kodratnya sendiri yangs ejati, dan menjadi Buddha di sini dan kini (Y.P. Mei, 1988: 20). Pada hakikatnya Buddhisme $C h^{\prime}$ an teguh dalam kepercayaan bahwa pikiran harus dibebaskan dari kekusutan dan harus dijaga agar tetap murni dan cerah. Dengan itu pikiran dapat menangkap kebenaran mendasar alam semesta, dan secara demikian dapat memperoleh kodrat Budha, nirwana atau keselamatan jiwa.

Buddhisme Ch'an banyak dipengaruhi Taoisme, begitu pula Buddhisme berpengaruh mendalam terhadap kesenian, kesusasteraan, dan sikap bangsa Cina dalam menghadapi kehidupan. Munculnya Neo-Konfusianisme dikemudian hari yang secara sepintas merupakan penolakan terhadap perkembangan dan pengaruh Buddhisme dalam masyarakat dan sistem kenegaraan, namun juga sebagai akibat dari rangsangan dan tantangan Buddhisme Ch'an.

Buddhisme banyak berbaur dengan Konfusianisme dan Taoisme. Konfusianisme bertujuan untuk memperbaiki dan menyeimbangkan hubungan antar sesama manusia, khususnya dalam kehidupan bermasyarakat, berbangsa, dan bernegara. Manusia ideal menurut adalah chun tzu, the gentlemen, the superior men atau manusia paripurna. Peletak dasar Konfusianisme adalah Pangeran Chou, kemudian diteruskan oleh Konfusius pernah menyatakan bahwa: negara yang adil dan makmur dapat dicapai apabila para pejabat negara atau penguasa adalah orang-orang yang berkarakter baik dan orang-orang yang benar-benar baik dalam hal 
mentalnya. Kemampuan untuk menjadi pejabat yang baik tidak ditentukan oleh faktor keturunan, akan tetapi sangat ditentukan oleh karakter atau kecakapan serta pengetahuan seseorang. Karakter, kecakapan, dan pengetahuan itu dapat diperoleh melalui pendidikan, oleh karena itu pendidikan harus disebarluaskan, ditingkatkan kualitas maupun kuantitasnya (Creel, H.G, 1954: 111).

Pemikiran Buddhisme memainkan peranan yang penting dalam filsafat Cina sampai berkembangnya Neo-Konfucianisme, para pemikir Cina tertarik kepada Buddhisme. Sebagian besar di antara mazhab Buddhisme yang ada di Cina termasuk dalam cabang Mahayana. Namun demikian, aliran Hinayana juga mempunyai wakilnya. Jika mazhab Wei Shih dan San-lun menganjurkan kecenderungan India akan analisis dan abstraksi, maka mazhab T'ien t'ai dan Hua-yen yang berakar di bumi Cina sendiri memadukan kecenderungan akan sintesis dengan penyelarasan (Y.P. Mei, 1988: 18).

Pada hakikatnya Buddhisme Ch'an teguh dalam kepercayaan bahwa pikiran harus dibebaskan dari kekusutan dan harus dijaga agar tetap murni dan cerah. Dengan itu pikiran dapat menangkap kebenaran mendasar alam semesta, dan secara demikian dapat memperoleh kodrat Buddha, nirwana atau keselamatan jiwa, yang dapat diperoleh tidak hanya melalui Buddhisme, Taoisme atau Konfusianisme saja, akan tetapi perlu kelenturan untuk mensintesiskan ketiga filsafat tersebut.

Buddhisme Ch'an bercirikan Taoisme Cina berpengaruh mendalam terhadap kesenian, kesusasteraan, dan sikap bangsa Cina dalam menghadapi kehidupan. Munculnya Neo-Konfusianisme di kemudian hari yang secara sepintas merupakan penolakan terhadap Budhisme, sebetulnya juga sebagai akibat rangsangan dan tantangan Budhisme Ch'an. Lebih lanjut di dalam Buddhisme juga diajarkan tentang bodhisattva yang sering diartikan sebagai: "seseorang yang telah punya hak untuk masuk nirvana dan menjadi Buddha, akan tetapi mendahulukan haknya itu untuk memperingatkan orang yang masih di dalam semesta ini supaya mendapatkan penerangan dan bekerja untuk keselamatan mereka" (Creel, 1954). Ajaran ini memberikan suatu harapan hidup bahagia di masa yang akan datang 
yang dengan masuk nirvana yang dapat dicapai apabila manusia telah berhasil dalam hidupnya dan menjadi Buddha, manusia sudah mampu mengatasi kehidupan duniawi yang penuh dengan problematika dan tantangan hidup yang tiada henti-hentinya. Buddhisme di Cina juga mengajarkan hidup sederhana dan kalau perlu manusia berusaha untuk menghilangkan keinginan-keinginan agar dapat mengatasi hidup yang penuh dengan penderitaan. Citacita yang ingin dicapai adalah agar manusia terhindar dari proses reinkarnasi yang tiada habisnnya yang disebabkan oleh keterikatannya dengan keinginan-keinginan. Manusia bermaksud untuk mencapai nirvana, dengan lebih dulu memperoleh pencerahan dan menjadi boddhisattva, serta bekerja untuk membantu sesama manusia untuk memperoleh keselamatan.

Hal ini sesuai dengan kecenderungan filsafat Cina yang berusaha untuk memperbaiki dan menyeimbangkan hubungan antar sesama manusia, hubungan antara manusia dengan masyarakat, bangsa, dan negara. Kecenderungan humanistik ini menjadikan manusia sebagai pusat segala-galanya dan kemampuan manusia perlu dikembangkan sedemikian rupa sehingga melalui daya kreatifnya yang rasional akan mampu menghasilkan hal-hal yang bermanfaat untuk meningkatkan kualitas kehidupan manusia itu sendiri. Namun demikian, di lain pihak manusia kadang kala khilaf bahwa problem-problem yang dihadapi manusia makin kompleks karena hasil perkembangan ilmu pengetahuan dan teknologi dalam pemanfaatnnya tidak dikembalikan pada kepentingan manusia justru akan mengancam kelangsungan hidup manusia itu sendiri. Hal ini merupakan motivasi bagi Buddhisme di Cina untuk lebih menekankan aspek spiritual dalam kehidupan manusia.

Dewasa ini Buddhisme di Cina juga dipandang sebagai pengembangan kehidupan spiritual untuk mencapai kebahagiaan sejati melalui meditasi. Meditasi dilakukan untuk mengubah diri sendiri dalam mengembangkan kualitas kesadaran, kebaikan dan kebijaksanaan dalam rangka untuk menemukan kedamaian perasaan dan pikiran.

Wilayah Tibet sebagai daerah otonomi di Cina, yang mayoritas penduduknya penganut Buddhisme yang dikenal dengan Tibetan 
Buddhisme dibawah kepemimpinan tokoh spiritualnya Dalai Lama. Hal ini merupakan daya tarik tersendiri bagi warga dunia untuk mengunjungi wilayah tersebut karena memiliki kekhasan dan keunikan tersendiri. Penganut Buddhisme di Cina dewasa ini lebih dari seratus juta orang yang pada dekade yang lalu terdiri atas orang tua, namun sekarang banyak generasi muda yang berpendidikan dan sukses dalam profesinya mulai tertarik dan menjadi penganut Buddhisme. Kelompok muda ini sering mengadakan aktivitas keagamaan di Vihara untuk meningkatkan kualitas kehidupan spiritual. Buddhisme menddorong manusia untuk menemukan jalan sendiri dalam mencapai pencerahan melalui kualitas kehidupan spiritual. Buddhisme mengajarkan bagaimana cara menemukan kedamaian hidup melalui kembali kedalam batin untuk mencerahkan hati.

\section{NEO-KONFUSIANISME SEBAGAI BENTUK PENGARUH BUDDHISME DI CINA}

Neo-Konfusianisme lahir sebagai salah satu bentuk keprihatinan dan reaksi kaum Konfusianis terhadap berkembangnya Buddhisme. Neo-Konfusianisme berupaya untuk menciptakan bentuk yang rasional dari Konfusianisme terhadap unsur-unsur mistis Taoisme dan Buddhisme. Neo-Konfusianisme berusaha untuk mengarah ke hal-hal yang secara konkret dihadapi manusia baik dalam bidang kehidupan masyarakat dan bernegara, terutama dalam bidang ekonomi dan pemerintahan. Neo-Konfusianisme juga memiliki kecenderungan humanistik yang kuat terhadap kehidupan manusia. Dalam hubungan ini W. T. de Bary menuliskan bahwa:

Neo-Connfucianism was clearly a new development, borrowing much from Buddhism and Taoism in order to supplement and expand the teachings received from the classical exponents of this school; whereas the more practical thought of the Sung school seemed, on the surfsce at least, to follow traditional lines, dealing with age-old Chinese institutions and with social problems which had been often met and handled in the same way before (Wright, Arthur, F, 1953: 81). 
Tokoh-tokoh Neo-Konfusianisme yang telah berjasa mengembangkan ajarannya antara lain: Shao Yung, Chou Tun-yi, Chang Tsai, Ch'eng Hao, Ch'eng I, Ch'u Hsi, dan Lu Hsiang Shan. Shao Yung berusaha untuk menafsirkan kosmologi yang termuat dalam I Ching. Alam semesta terjadi secara evolusi, evolusi berasal dari The Great Ultimate, $\mathrm{Li}$ atau Tao, melalui prinsip yin dan yang, jiwa, angka, bentuk, dan akhirnya mencapai hal-hal yang bersifat materi. Segala sesuatu yang ada di dunia ini berisi prinsip-prinsip, dan prinsipprinsip itulah yang memimpin segala sesuatu. Lebih lanjut dijelaskan bahwa manusia merupakan unsur yang paling penting di dalam alam semesta, manusia berasal dari The Supreme Ultimate melalui prinsip yin yang.

Chou Tun Yi, sebagai perintis aliran Neo-Konfusianisme, mengajarkan konsep wu-Non Being dari Taoisme dengan ajaran Jen (Kemanusiaan) dan Yi (Kelayakan) dari Konfusianisme. Menurut pendapatnya, bahwa di dalam alam semesta itu terdapat dua prinsip $l i$ (immaterial) dan $c^{\prime} i$ (extensi material).

Ch'ang tsai (1020-1077) adalah tokoh Neo-Konfusianisme yang mengajarkan bahwa kodrat manusia itu baik tetapi dibelenggu oleh keinginan dan emosi. Inilah yang merupakan salah satu sebab mengapa manusia dalam hidupnya sering menderita. Lebih lanjut diajarkan bahwa alam semesta itu pada dasarnya hanya satu akan tetapi dapat dimanifestasikan dalam banyak benda yang berbeda satu dengan yang lain. Yang satu itu disebut $c h^{\prime} i$. Surga dan Bumi itu adalah $C h ' i$ sehingga $C h$ 'ang tsai juga dikenal sebagai seorang monis. $C h^{\prime} i$ ada dua jenis yaitu ada yang tidak terbatas jumlahnya sama untuk semua benda, dan ada ch'i yang terbatas ada pada setiap individu yang disebut sebagai physical nature yang membelenggu manusia sehingga manusia tidak dapat mencapai kebahagiaan. Untuk itu manusia perlu melepaskan diri dari cengkeraman ch'i dengan jalan identifikasi dengan diri sendiri.yang kemudian perlu dikembangkan rasa cinta terhadap alam semesta beserta seluruh isinya (Lasiyo, 1993; 26-27). Apabila manusia sudah dapat melepaskan diri dari belenggu physical nature, maka dia akan memperoleh kebahagiaan dan memiliki karakter dan memiliki ch'i yang bersifat universal. Kebahagiaan orang bijaksana adalah hasil yang sewajarnya dari keadaan jiwanya yang digambarkan 
oleh Chou Tun Yi seperti "kosong dalam diam dan terus terang dalam gerak", dan digambarkan oleh Ch'eng hao sebagai "impersonal, imparsial, dan respons terhadap segala sesuatu secara spontan", ia tidak menikmati tao, ia hanya menikmati apa adanya dirinya (Fung Yu lan, 1937: 377).

Ch'eng Hao sebagai filsuf yang memiliki kecerungan idealistik, mungkin karena ia banyak belajar tentang filsafat Taoisme dan Buddhisme. Ia berusaha untuk menginterpretasikan Jen atau kemanusiaan kepada hal-hal yang bersifat metafisik. Jen ini tergantung kepada relasinya di alam semesta, karena manusia pada dasarnya memiliki kodrat baik. Manusia hendaknya dapat berbuat baik sebagai implementasi kodratnya dalam kehidupan masyarakat.

Ch'eng I, sependapat dengan Ch'eng Hao, bahwa kodrat manusia itu baik. Jen merupakan tanda adanya kesatuan yang utuh antara manusia dengan alam semesta, oleh karena itu untuk menjaga kehidupan yang selaras dan harmonis dengan alam semesta maka jen dijadikan dasar yang paling fundamental bagi setiap tindakan manusia. Ch'eng berpikir bebas, ia membedaklan dengan tajam antara Li (principle) dan Ch'i (matter). Lebih lanjut ia mengajarkan bahwa:

1. Evolusi yang berlangsung secara terus menerus akan menghasilkan benda benda yang baru.

2. Setiap benda memiliki prinsip $(L i)$ sendiri

3. Manusia yang tahu tentang prinsip benda benda yang berdiri sendiri, maka ia akan tahu tentang prinsip-prinsp yang ada dalam dirinya sendiri.

4. Untuk mengetahui tentang prinsip-prinsip kemanusiaan, manusia cukup meneliti ke dalam dirinya sendiri karena semuanya dapat dicapai dan ditemukan oleh dirinya sendiri (Wade Baskin, 1974: 473).

Chu Hsi sebagai seorang filsuf Neo-Konfusianisme yang cukup berpengaruh berpendapat bahwa segala sesuatu di dunia ini terdiri atas dua hal yaitu $L i$ dan $C h^{\prime} i$. Pertama, $L i$ adalah prinsip rokhani yang menembus seluruh alam semesta dan pada saat yang sama berada dalam setiap individu, serta $L i$ yang membedakan setiap individu yang satu dengan individu yang lain (Huang Sin Chi, 1944: 19). Li pada 
setiap makhluk merupakan bagian dari $L i$ yang besar. Menurut Chu Hsi, prinsip yang sempurna adalah The Supeme Ultimate (T'ai Chi), The Supreme Ultimate ini adalah $L i$ dari Surga dan Bumi dan sepuluh ribu benda-benda (Wu Yi, 1986: 87). Li dapat diartikan pula sebagai hukum yang mengontrol perjalanan dan gerak alam semesta. Nampaknya ajaran Ch'u Hsi tentang Li mirip dengan ajaran Taoisme tentang Tao. Tao artinya suatu Dzat Asali yang melahirkan Surga dan Bumi dan meliputi seluruh alam semsta, Tao merupakan asal sekaligus tempat kembalinya segala sesuatu yang ada di alam semsta ini. Kedua, $C h^{\prime} i$ dapat diartikan sebagai substansi atau kebendaan. $C h^{\prime} i$ berdiri sendiri yang mampu menghasilkan eksistensi segala sesuatu dan memapu mengadakan perubahan terhadap segala sesuatu itu. Hal-hal yang bersifat kebendaan inilah yang dapat membelenggu manusia untuk memahami $\mathrm{Li}$ atau Prinsip, sehingga manusia akan mengalami kesulitan dalam mencapai kebahagiaan. Manusia menjadi menderita karena $C h^{\prime} i$.

Chu Hsi berpendapat bahwa manusia sejak lahir mememiliki Ming Te atau kodrat manusia yang merupakan karunia Surga. Kodrat manusia itu seperti mutiara yang sangat berharga, namun terdapat dalam air kotor sehingga tidak dapat dilihat oleh mata. Oleh karena itu, apabila air kotor itu dibuang maka mutiara tersebut akan memancarkan sinar seerti aslinya. Manusia hendaknya selalu beruasha untuk dapat mengenali kodratnya, karena hal itulah sebenarnya yang diinginkan Surga. Manusia pada dasarnya selalu berada dalam cengkeraman materi dan keinginan. Sehingga kodratnya menjadi terbelenggu (Gardner: 1986: 53)

Dalam hubungan ini, Chu Hsi berbeda dengan Buddhisme yang selalu mengajarkan agar manusia melakukan meditasi untuk mencapai pencerahan, sedangkan Chu Hsi mengajarkan bahwa manusia selalu dalam cengkeraman $c h^{\prime} i$, dan hal ini merupakan gejala psikologis. Untuk itu diperlukan upaya dan usaha untuk kembali dan memahami kodrat manusia yang merupakan karunia Surga yaitu dilakukan dengan jalan introspeksi. Introspeksi dilakukan dengan usaha yang sungguh-sungguh yaitu dengan mengamati benda-benda yang ada di luar dirinya melalui ko wu. Ko wu diartikan sebagai suatu studi yang sempurna terhadap manifestasi berbagai macam prinsip benda-benda 
sampai pada pengertian tentang prinsip itu sendiri. Jadi dengan perluasan kodratnya itu sendiri (Gardner, 1986: 58).

Dengan kata lain dapat dinyatakan bahwa manusia itu mempunyai li sendiri yang berbeda dengan li makhluk lain. $L i$ dalam diri manusia terbelenggu oleh $c h ' i$. Untuk mencapai kebahagiaan maka manusia harus mengenal $l i$ nya lebih dahulu supaya $l i$ dapat terlepas dari belenggu $c h^{\prime} i$. Untuk mengenal $l i$ yang terdapat dalam diri seseorang, maka manusia perlu menyelidiki dan mengetahui $l i$ dari semua makhluk hidup. Setelah itu maka dia akan menjadi orang bijaksana dan mendapatkan kebahagiaan, dalam arti hidupnya tidak tergantung kepada hal-hal yang bersifat kebendaan.

Lebih lanjut Chu Hsi mengajarkan Konsep tentang Dzat Tertinggi juga diungkapkan dengan ide tentang T'aiChi, "Yang Maha Agung", dimana dalam Konfusianisme dikembangkan oleh beberapa filsuf. Ini dikemukakan oleh Chang Tsai, dan pada awalnya bermakna satu kekuatan material. Shao Yung di kemudian hari mengatakan bahwa itu berarti jiwa, makna yang dapat dipahami hanya manakala jiwa dalam keadaan tenang (Chan, 1987: 52). Secara lebih khusus, dia menyatakan bahwa T'aiChi, meskipun merupakan konsep tunggal, menghasilkan dua kekuatan (yin dan yang), kemudian bilangan dan seluruh bentuk, dan akhirnya objek-objek konkret. Jadi bagi dia, T'aiChi merupakan sumber serta totalitas bentuk dan bilangan. T'aiChi mengandung kekuatan material dan bentuk fisik Langit, Bumi, dan manusia.

Kemudian, konsep T'aiChi dipopulerkan oleh Chu Hsi. Dia meringkaskan dalam satu kata: "prinsip". Chu Hsi mengatakan "Ia tidak lain adalah prinsip Langit dan Bumi serta puluhan ribu bendabenda." Chan (1987: 53) berkomentar bahwa karena "prinsip" adalah universal dan segala sesuatu memiliki prinsipnya, itu berarti bahwa Yang Maha Agung itu tunggal sekaligus jamak. Sehingga ia meliputi segala benda sebagai satu keseluruhan dan sekaligus setiap benda individu; itu diliputi di dalam Yang Maha Besar. Alam semesta sebagai sebuah makrokosmos, sedangkan segala sesuatu yang berada di dalamnya sebagai mikrokosmos. Ide ini terpengaruh oleh ajaran Mencius, bahwa segala sesuatu itu lengkap di dalam diri manusia. Fung Yu Lan (1953: 537) menulis bahwa T'aiChi itu tercipta dari prinsip-prinsip segala benda di alam semesta, menyatu di dalam satu 
keseluruhan yang tunggal, sehingga semua prinsip hadir di dalamnya.

Chu Hsi mengatakan bahwa T'aiChi memiliki seluruh prinsip yang mengatur lima unsur yin dan yang, dengan demikian tidak ada sesuatu yang kosong. Baik Penguasa Langit maupun T'aiChi adalah pencipta. Penguasa Langit adalah transenden, sedangkan T'aiChi adalah imanen dan transenden. T'aiChi adalah imanen di dalam proses penciptaan melalui evolusi prinsip. Dengan begitu, segala sesuatu memiliki prinsipinya sendiri, yang diturunkan dari T'aiChi. T'aiChi transenden karena masih memiliki prinsipnya sendiri dan mengada. Segala sesuatu yang ada di alam semesta akan kembali kepada T'aiChi.

Chu Hsi menguraikan empat ciri khas T'aiChi. Pertama, bersifat kodrati dan bukan merupakan hasil dari aksi pengada yang lain. Dengan demikian, ia Maha Tinggi. Kedua, ia tidak terbatas dan abadi. Ketiga, ia adalah kebaikan yang tertinggi dan merupakan kesempurnaan. Terakhir, ia memiliki aktivitas dan ketenangan. Atas dasar itu, dia menjelaskan bahwa semua aktivitas adalah aktivitas. T'aiChi dan seluruh ketenangan adalah ketenangannya (Aimin Teng dalam Chan, 1986: 94-95). Dengan cara yang sama, Huang Shiu-chi (1974: 280) juga mengklasifikasi ciri khas T'aiChi menjadi empat: 1) ia telah ada sejak awal alam semesta; 2) ia imanen dan melekat dalam segala sesuatu; 3) kebaikan dan ketulusannya tidak dapat dilampaui; dan 4) ia abadi dalam proses yang berkesinambungan dalam kaitannya dengan gerak dan diam.

Menurut teori Chu Hsi, di dalam T'aiChi terhadap WuChi (Yang Tidak Berakhir atau Yang Tanpa Batas) dan di luar T'aiChi tidak terdapat WuChi. Chen Ch'un (1986: 119) mengemukakan bahwa umumnya, hanya ada satu prinsip yang tidak terbedakan: Yang Maha Agung. Meskipun demikian, ketika orang berbicara secara terpisah tentang Langit, manusia, dan benda- benda, mereka masing-masing memiliki prinsipnya sendiri dan kegungannya sendiri.

Lu Hsiang Shan berbeda dengan Chu Hsi, ia berpandangan bahwa segala sesuatu itu hanya memiliki $l i$, dan untuk mengetahui dan menyelidiki $l i$, manusia cukup memeriksa atau mengenal $l i$ yang ada di dalam dirinya sendiri. Lu Hsiang Shan hampir sama dengan Mensius yang menyatakan bahwa segala sesuatu itu lengkap di dalam diriku (Creel, H.G, 1954: 210). Introspeksi sangat diperlukan agar 
manusia dapat mencapai kebahagiaan, setiap waktu manusia harus meneliti dan mengevaluasi tindakan-tindakan yang telah dilakukan dan membuat perencanaan yang matang tentang hal-hal yang dilakukan pada masa yang akan datang.

Lu Hsiang Shan dalam hubungan ini pernah mengatakan bahwa: "Alam semesta adalah jiwaku dan jiwaku adalah alam semesta "( Fung Yu Lan, 1947: 193), artinya bahwa segala sesuatu di alam semesta dapat dipikirkan oleh manusia, dan semua yang dipikirkan oleh manusia sesuai dengan yang ada di alam semesta. Sikap yang demikian ini sebenarnya kurang menguntungkan bagi perkembangan ilmu pengetahuan modern, akan tetapi sangat bermanfaat bagi ketenteraman manusia. Dalam mencapai kebahagiaan, Lu Hsiang Shan selalu menitik beratkan agar manusia melakukan introspeksi dengan mengenal li yang terdapat di dalam diri sendiri.

Berdasarkan garis besar pemikiran para tokoh NeoKonfusianisme menempatkan pengertian $l i$ sebagai prinsip atau hukum, hampir sama dengan istilah dharma dalam Buddhisme. Dalam Buddhisme dharma berada dalam semua kejadian, akan tetapi tidak memiliki substansi.Pengertian $l i$ atau prinsip dalam NeoKonfusianisme bahwa $l i$ terdapat dalam segala sesuatu akan tetapi terdapat substansi yang realistis. Dalam hubungan ini NeoKonfusianisme berusaha untuk menerapkan konsep dan ide-idenya dalam realitas kehidupan dan kemanusiaan sebagai tema sentral pemikiran filsafat Cina.

Ajaran Neo-Konfusianisme melontarkan kritik terhadap Buddhisme dan Taoisme dengan mangajarkan Metafisika dan Etika. Jika Buddhisme dan Taoisme mempergunakan ajaran Metafisika untuk pengembangan spiritual, pencerahan agama, keabadian, Metafisika dalam Neo-Konfusianisme untuk mengembangkan ajaran Etika yang rasionalis, dengan harapan dapat diterapkan dalam kehidupan seharihari untuk menciptakan ketertiban dalam masyarakat.

\section{SIMPULAN}

Berdasarkan analisis dan pembahasan tentang pengaruh Filsafat Buddhisme terhadap Neo-Konfusianisme di Cina, maka kesimpulan yang dapat diperoleh antara lain: pertama, Buddhisme dari India dapat 
diterima dan berkembang pesat di Cina disebabkan kondisi masyarakt yang tidak puas terhadap filsafat Konfusianisme dan Taoisme. Buddhisme dapat memberikan penghiburan kepada rakyat untuk memperoleh kebahagiaan hidup.

Kedua, Neo-Konfusianisme muncul sebagai bentuk reaksi dari para penganut Konfusianisme terhadap perkembangan Buddhisme di Cina. Reaksi ini muncul karena Buddhisme tidak mampu memperbaiki kesejahteraan masyarakat. Ketiga, para penganut Konfusianisme menyadari bahwa untuk bersaing dengan Buddhisme perlu memberikan pemikiran filsafat yang diambil dari pemikiran filsafat Cina klasik dan disesuaikan dengan situasi dan kondisi masyarakat.

Keempat, Neo-Konfusianisme mengajarkan Metafisika dan Etika yang masih bersifat teoritis sehingga belum berhasil memperbaiki perekonomian dan kesejahteraan rakyat. Kelima, Neo-Konfusianisme dalam ajarannya merekonstruksi kembali pemikiran filsafat yang dianut masyarakat dan mengambil beberapa pemikiran Taoisme dan Buddhisme.

\section{DAFTAR PUSTAKA}

Allinson, Robert E (ed.), 1989, Understanding the Chinese Mind: The Philosophical Roots. Oxford University Press, Oxford.

Baskin, Wade, 1974, Classics in Chinese Philosophy, Adam \& Co, New Jersey.

Ch'an, Wing-tsit, 1987, A Source Book in Chinese Philosophy, Princeton University Press, Princeton.

Chan Wing-tsit (ed.), 1986, Chu Hsi and Neo Confucianism, University of Hawaii Press, Hawaii

Chan Wing-tsit, 1987, "Chinese Religion and Philosophical Texts" The Encyclopedia of Religion Vol. 3 Ed. M. Eliade, Macmillan, New York, hal: 305-312

Chai, Ch'u and Chai, Winberg, 1975, The Story of Chinese Philosophy, Washington Square Press, New York.

Cheng, Chung-ying,1995, "Chinese Metaphysics as Non-metaphysics Confucian and Taoist Insight into the Nature of Reality" dalam Allinson, Robert, E., Understanding the Chinese Mind: The 
Philosophical Roots, Oxford University Press, Oxford.

Cohen, Alvin, P, 1987, "Chinese Religion: Popular Religion" The Encyclopedia of Religion Vol. 3 Ed M. Eliade, Macmillan, New York, hal: 289-296

Creel, H. G., 1954, Chinese Thought from Confucius to Mao Tse-tung, Eyre \& Spottiswoode, London.

Dalai Lama and Cutler. Howard C, M.D, 2006, The Art of Happines. A Hand Book of Living, Griffin Press, Adelaide.

Fung Yu-lan, 1947, A History of Chinese Philosophy, Vol. I, Translated by Derk Bodde, George Allen \& Unwin Ltd, London.

Fung Yu-lan, 1953, A History of Chinese Philosophy, Vol. II, Translated by Derk Bodde, George Allen \& Unwin Ltd, London 1960, A Short History of Chinese Philosophy, Translated by Derk Bodde, George Allen \& Unwin Ltd, London.

Gardner, Daniel, K., 1986, Chu Hsi and Ta-Hsueh, Council on East Asian Studies, Havard University, USA

Huang Siu-chi, 1944, Lu Hsiang Shan, A Twelfth Century Chinese Idealist Philosopher. American Oriental Society. New Haven.

Kim Yong Choon, 1973, Oriental Thought: an Introduction to the Philosophical and Religious Thought. Roman and Little Field, New York.

Lasiyo, 1993, Neo-Konfusianisme. Yayasan Penerbitan Fakultas Filsafat UGM, Yogyakarta

2013, Pemikiran Filsafat Timur, Lintang Pustaka Utama, Yogyakarta

, 2015, The Emergence of Confucianism in Indonesia, Lintang Pustaka Utama, Yogyakarta

Legge, James, 1893, The Chinese Classics, Vol I, Oxford University Press, Oxford

Mudji Sutrisno, 1993, Jelajah Hakikat Pemikiran Timur. Gramedia, Jakarta Mei, Y.P., 1988, The Pageant History of Chinese Philosophy, Alih bahasa:

Soejono Soemargono, Fakultas Filsafat UGM, Yogyakarta

Smith, Huston, 1985, The Religions of Man, Penerjemah: Saafroedin Bahar, Yayasan Obor, Indonesia, Jakarta

Wright, Arthur, F, 1953, Studies in Chinese Thought. The University Chicago Press, Chicago 
Wu, Yi, 1986, Chinese Philosophical Term, University Press of America. USA

Thompson, Laurance, G, 1989. Chinese Religion: an Introduction, 4th Ed. Belmont, Calif, Wadsworth. 